\title{
НАПРАВЛЕНИЯ ФОРМИРОВАНИЯ УСТОЙЧИВЫХ ТЕНДЕНЦИЙ К ЭКОНОМИЧЕСКОМУ РОСТУ, ЦИФРОВИЗАЦИИ И ПРОГРЕССУ В СТРОИТЕЛЬНОЙ ОТРАСЛИ
}

Меджитов С. C., Адаманова 3. O. ГБОУВО РК «Крымский инженерно-педагогический университет имени Февзи Якубова», г. Симферополь

B статье произведено исследование подходов по формированию тенденций устойчивого развития строительной отрасли. Рассмотрень направления оптимизации государственной политики в данной сфере, выявлен комплекс мер по преобразованию самого строительного комплексу и развитие его инфраструктуры по формированию благоприятной деловой средь, рассмотрены преобразования непосредственно в строительном комплексе по восстановлению производственных мошностей, внедрению передовых методов организации и ведения работ, разработка ресурсных и энергосберегающих технологий.

Ключевые слова: устойчивое развитие, строительная отрасль, государственная политика, деловая среда, промышленность строительных материалов, механизации строительства.

Введение. В условиях мирового финансово-экономического кризиса изучение условий формирования и обеспечения стабильного функционирования строительной отрасли становится чрезвычайно актуальным. Строительная отрасль - это инфраструктура, которая влечет за собой цепочку развития многих других отраслей народного хозяйства. Данные аспекты способствуют необходимости создания на государственном уровне направления формирования тенденций устойчивого развития строительной отрасли.

Цель исследования - разработать направления оптимизации формирования тенденций устойчивого развития строительной отрасли.

Изложение основного материала. Принципы, методы и критерии управления любыми активами предприятия в основном определяются особенностями отрасли, к которой они принадлежат. Строительство является ключевой сферой национальной экономики, результаты деятельности которой имеют не только важное экономическое значение, но и социальное. Оно характеризуется высокой материалоемкостью и длительным производственным циклом, наличием неравномерности потребления материальных ресурсов по календарным периодам года, усиливает риск роста цен и обусловливает актуальность исследования тенденций и проблем отрасли, взаимосвязи ее с производством строительных материалов. 
Однако на сегодняшний день предприятия строительной отрасли сопровождает ряд проблем. Среди факторов, негативно влияющих на развитие строительного комплекса, следует отметить такие, как:

- Отсутствие информационного обеспечения строительного рынка. Информация является разрозненной, противоречивой, недостоверной, что создает препятствия для реализации проектов строительства или реконструкции, внедрения и использования новейших технологий и материалов, инвестирования. Перечисленное отрицательно влияет на качество строительных работ и услуг. Также следует отметить прямую зависимость конкурентоспособности произведенной продукции от наличия качественного информационного потока.

- низкий уровень квалификации специалистов. Этот фактор тесно связано как с общим уровнем строительной образования, который в последнее время значительно ниже и имеет негативную тенденцию, так и с недостаточным связью науки и практики, несовершенством информационного обеспечения о новейших разработках и исследованиях со стороны науки.

- сокращение объемов инвестирования. В связи с повышением рисков вследствие высокой изменчивости окружающих условий, экономической и политической нестабильности, трансформационных процессов в экономике Республики Крым значительно сократился объем иностранного финансирования и кредитования. Иностранные инвесторы сократили финансовый поток, ожидая более стабильных условий и сокращения рисков, обусловленных санкционным периодом, действующим на территории региона в 2014 г.

- большая часть расходов в производстве строительной продукции и услуг приходится на материальные затраты и оплату тепло и энергоснабжения. Высокая стоимость материалов, используемых в производстве, подорожание тепло и энергоносителей приводят к росту себестоимости продукции, услуг, товаров строительного рынка. Ограниченные финансовые возможности населения в отношении получения строительной продукции и рост стоимости продукции вызывают сокращение спроса и объемы реализации продукции.

Эскалация экологической ситуации также оказывает определенное влияние на отрасль, которая усугубляется влиянием антропогенного фактора и создает дополнительные трудности для устойчивого развития строительной отрасли.

Важным фактором, препятствующим устойчивому развитию строительной отрасли в Республике Крым, является наличие нечетких тенденций в еe дальнейшем развитии, отсутствие соответствующей государственной поддержки и несовершенство законодательной базы, регулирующей эти вопросы [1, с. 17].

На наш взгляд, необходимо разработать ряд мер, которые способствовали бы формированию устойчивых тенденций развития строительной отрасли. Такие меры, направленные на непосредственное преобразование отраслей 
строительной промышленности, могут, по нашему мнению, включать следующие мероприятия:

1. В сфере жилищного строительства. Основная проблема, препятствующая реконструкции и сносу старых домов (во многих городах критическое аварийное состояние жилых зданий XIX века является большой проблемой), заключается в нехватке средств на государственном и местном уровнях при низком интересе со стороны представителей бизнеса. Такая ситуация обусловлена отсутствием на государственном уровне соответствующей программы, которая обеспечивала бы деловой интерес [3].

Необходимо разработать и внедрить новые технологии для строительства домов качественно нового поколения, в основе которых должны быть экологические и энергосберегающие технологии жизнеобеспечения, технологии повышения надежности функционирования таких домов, и система поддержки и жилищный фонд городов и поселков и т. д. [3].

2. В области промышленного и других видов строительства. В каждом конкретном направлении следует разработать местную стратегию строительства для промышленности и транспорта. Итак, при массовом внедрении принципиально новых технологий высокопроизводительного оборудования необходимо совершенствовать планировочные решения зданий в направлении повышения их гибкости и универсальности, чтобы обеспечить простоту адаптации зданий к частым изменениям технологических процессов с минимальными затратами. объем работ по реконструкции и модернизации здания.

3. В сфере промышленности строительных материалов. Материальнотехническое обеспечение строительного комплекса региона напрямую связано с производством строительных материалов. Уровень и эффективность строительства также зависит от качества строительных материалов. Перед отраслью стоит серьезная задача по укреплению своих позиций как продукции отрасли на внутреннем рынке [4, с. 89].

Устойчивое развитие промышленности строительных материалов, а вместе с ней и всей строительной отрасли за счет обновления основных фондов предприятий промышленности строительных материалов с переходом на более высокий уровень их технического оснащения.

4. В области развития технологии и механизации строительства можно выделить разработку и совершенствование существующих форм и методов организации строительства (долгосрочные потоки, метод полного блока, узловой метод, сдвиг, экспедиционный метод); разработка научных принципов и методов технико-экономического обоснования рациональных технологических решений и форм организации подготовительного и основного периодов в строительстве (реконструкции); контроль и оценка качества строительно-монтажных, ремонтно-строительных работ, конструкций зданий и сооружений.

Вывод. В качестве выводов исследования следует отметить следующее: государственная политика, направленная на формирование устойчивых 
тенденций экономического роста и экономического прогресса в строительной отрасли, предлагает модель, включающую комплекс мер по преобразованию самого строительного комплекса и степень поддержки, вовлеченной в развитие инфраструктуры отрасли и формирование благоприятной деловой среды. Основными тенденциями преобразований непосредственно в строительном комплексе являются: восстановление производственных мощностей, внедрение передовых методов организации и ведения работ, разработка ресурсных и энергосберегающих технологий. В плане мер по поддержке преобразований в строительной отрасли приоритет отдается мерам по повышению конкурентоспособности строительных предприятий, повышению научнотехнического потенциала отрасли.

\section{Список литературы}

1. Вертакова, Ю.В. Устойчивое развитие промышленных комплексов на основе модернизации механизма пространственного распределения экономических ресурсов / Ю.В. Вертакова. - М.: Русайнс, 2017. - 352 с.

2. Сенчагов, В.К. Инновационные преобразования как императив устойчивого развития и экономической безопасности России / В.К. Сенчагов. М.: Анкил, 2018. - 180 с.

3. Коряков А. Г. Научные подходы к формированию системы предпосылок для устойчивого развития отраслей отечественной промышленности // А. Г. Коряков // ТДР. 2012. №3. [Электронный ресурс]. Режим доступа: URL: https://cyberleninka.ru/article/n/nauchnye-podhody-kformirovaniyu-sistemy-predposylok-dlya-ustoychivogo-razvitiya-otrasleyotechestvennoy-promyshlennosti (дата обращения: 16.12.2019).

4. Мюррей, П. Индивидуальный подход к устойчивому развитию / П. Мюррей. - М.: Бином. Лаборатория знаний, 2017. - 749 с. 